\title{
Alternatives to potentially inappropriate medications for use in e-prescribing software: triggers and treatment algorithms
}

\author{
Anne L Hume, ${ }^{1}$ Brian J Quilliam, ${ }^{1}$ Roberta Goldman, ${ }^{2,3}$ Charles Eaton, ${ }^{2,3}$ \\ Kate L Lapane ${ }^{4}$
}

- Additional figures are published online only. To view these files please visit the journal online (http:// qualitysafety.bmj.com).

1Department of Pharmacy Practice, College of Pharmacy, University of Rhode Island, Kingston, Rhode Island, USA

${ }^{2}$ Center for Primary Care and Prevention, Memorial Hospital of Rhode Island, Pawtucket, Rhode Island, USA

${ }^{3}$ Department of Community Health, Warren Alpert Medical School of Brown University, Providence, Rhode Island, USA ${ }^{4}$ Department of Epidemiology and Community Health, Virginia Commonwealth University, Richmond, Virginia, USA

Correspondence to Kate L Lapane, Department of Epidemiology and Community Health, Virginia Commonwealth University, 830 East Main Street, Fifth Floor, Richmond, VA 23298, USA; kllapane@vcu.edu

Accepted 31 May 2011 Published Online First 30 June 2011

This paper is freely available online under the BMJ Journals unlocked scheme, see http://qualitysafety.bmj. com/site/about/unlocked. $\mathrm{xhtml}$

\section{ABSTRACT}

Objective: To describe the development of evidencebased electronic prescribing (e-prescribing) triggers and treatment algorithms for potentially inappropriate medications (PIMs) for older adults.

Design: Literature review, expert panel and focus group.

Setting: Primary care with access to e-prescribing systems.

Participants: Primary care physicians using e-prescribing systems receiving medication history. Interventions: Standardised treatment algorithms for clinicians attempting to prescribe PIMs for older patients.

Main outcome measure: Development of 15 treatment algorithms suggesting alternative therapies.

Results: Evidence-based treatment algorithms were well received by primary care physicians. Providing alternatives to PIMs would make it easier for physicians to change decisions at the point of prescribing.

Conclusion: Prospectively identifying older persons receiving PIMs or with adherence issues and providing feasible interventions may prevent adverse drug events.

\section{INTRODUCTION}

Among independently living adults in the USA, over a quarter experience adverse drug events (ADEs) based on one cohort study. ${ }^{1}$ The estimates of ADEs are even higher in American adults over 65 years of age and receiving Medicare, the US federal healthcare program for older adults. ${ }^{2}$ An estimated US $\$ 887$ million is spent annually on preventable ADEs among Medicare recipients in the ambulatory setting. ${ }^{3}$ Given this significant burden of ADEs, identifying feasible interventions for reducing preventable ADEs in the private physician offices and other ambulatory care settings is important.

The medication use process includes prescribing, dispensing, administering, and monitoring the medication. The prescribing stage of the process is associated with over half of the errors associated with preventable ADEs. $^{2} 4$ Electronic prescribing, more commonly known as e-prescribing, has been proposed as a technology-based approach for reducing potentially preventable ADEs. E-prescribing is the direct computer-tocomputer transmission of prescription information from physician offices to community pharmacies. E-prescribing systems also allow for patient safety features including clinical decision support and sharing of patient pharmacy data across multiple prescribers. The technology has advanced features which allow a prescriber to access formulary information at the point of prescribing. With this technology, the physician writes a prescription for a patient using a computer, with the computer software alerting the prescriber when a potential drug-drug or drug-disease interaction might occur.

By the end of 2009, 25\% of all officebased prescribers in the US were using e-prescribing and about $18 \%$ of eligible prescriptions were prescribed electronically. ${ }^{5}$ Most US prescribers are in solo and small group practices which have continued to lag in the use of e-prescribing and other advanced features such as accessing formulary information. These advanced features are important for efficient primary care practice. Older Americans may have one of many different types of private insurance plans that provide the drug coverage 
commonly known as Medicare Part D plans. ${ }^{6}$ These insurance plans may have their own unique formulary of covered medications.

Continued growth in e-prescribing is anticipated with the passage of the American Recovery and Reinvestment Act in 2010. This legislation has provided governmental funding and other incentives to encourage the more widespread use of health information technology (HIT) including e-prescribing. With the growing use of e-prescribing and HIT in the USA, it has also become apparent that the technology must be clinically relevant. For example, computer alerts that commonly tell a busy prescriber about drug interactions that are clinically insignificant may result in the prescriber ignoring the alerts, including those that are very important. ${ }^{7}$

To address previous issues with prescribing alerts, we designed tailored triggers and alternative treatment options specific for older patients as part of a larger e-prescribing study. Our goal was to improve drug use in older adults by alerting prescribers to potentially inappropriate medications (PIMs), as well as to suggest potentially safer alternatives at the point of prescribing. Focus groups were also conducted to identify healthcare providers' opinions about drug alerts embedded within e-prescribing applications. The purpose of the current paper is to describe the development of evidence-based treatment algorithms for recommending alternative treatments to PIMs, and to provide the actual treatment algorithms which are being used in a large-scale e-prescribing study.

\section{METHODS}

The study protocol was approved by the Institutional Review Boards of Virginia Commonwealth University, University of Rhode Island, and Memorial Hospital of Rhode Island.

\section{Triggers for PIMs}

PIMs were identified first by reviewing the 2003 update of the Beers criteria drugs with all drugs initially being considered. ${ }^{9}$ Although many medications may potentially be inappropriate for older adults, such as the use of statins at the end of life, we sought to identify medications that had well accepted concerns associated with their use, either in terms of their safety or limited efficacy.

An informal email survey of community pharmacists practicing in Rhode Island and Massachusetts was conducted. The seven pharmacists were alumni of the University of Rhode Island College of Pharmacy and served as preceptors for pharmacy students on their required community pharmacy experiential rotations. The pharmacists worked for the three major drug store chains in the USA. The pharmacists were asked to review the list of 39 PIMs from the Beers criteria and to indicate what drugs were being dispensed in their pharmacies. This resulted in the number of PIMs being reduced from 39 to 15 based on limited prescribing of many of the identified drugs. One author (ALH) also reviewed the list for more commonly prescribed PIMs, as well as two other pharmacy faculty members with clinical and research expertise in geriatrics and one pharmacy faculty member with expertise in community pharmacy practice.

\section{Treatment algorithms for alternatives to PIMs}

An extensive literature search was conducted to provide the basis for making alternative recommendations for PIMs. The treatment algorithms were intended to serve as a quick reference for clinical decision-making. Early on in this project, one of the authors (ALH) with extensive experience in primary care geriatrics developed an initial draft algorithm for each of the 39 PIMs for older adults. ${ }^{9}$ After discussion with the software vendor, this initial list was reduced to the 15 which were further developed.

The authors discussed the rationale and alternative recommendations listed in the algorithms, and the evidence upon which the recommendations were made. Revisions were made to the algorithms based on these discussions. The algorithms were reviewed by two additional pharmacy faculty members with clinical and research expertise in geriatrics, as well as by a pharmacy faculty member with expertise in community pharmacy practice. These individuals provided a careful review and recommendations for modification of the treatment algorithms. The rationale for suggested changes was discussed and agreement was reached about the final treatment algorithms. The research team then reviewed the algorithms for their general content and likely effectiveness as a prescribing alert. Judging the likely effectiveness of the alert was based primarily on the appropriateness of the alternative drugs proposed by the alert. This included consideration of the alternative drug's safety and effectiveness for the condition, availability as a generic drug, likely familiarity with primary care providers, etc. This assessment was also based on the experience of research team members who were pharmacists or physicians.

\section{Integration of trigger for PIM use in the real-time e-prescribing software}

The first stage of the process included meeting with the electronic prescribing software vendor to learn about what specific medication data were available, and how the information was captured. The goal was to identify patients prescribed (or soon to be prescribed) PIMs in 
the 'real-time' of the clinical encounter. As such, we needed to develop triggers based on information included in the commercial software. The development of triggers was focused on drugs that were potentially more serious. We also need to identify an approach within the existing software to both trigger and display the alternative suggestion without slowing down the software or adding to clinician burden to receive the messaging. We embedded the alerts into the e-prescribing software such that seeing the alerts did not require additional effort for prescribers. The alerts appeared on the main prescribing screen and as such did not require the physicians to push extra buttons to see the alerts. We had the alerts appear similarly to what appears when the physician attempts to prescribe medications that are not on the formulary of the patient's insurer. That is, a message appears alerting the prescriber that the medication is not on the formulary along with a box of alternative medications that are on the formulary.

In addition, we wanted the messages to be relevant and concise, as well as consistent with the software display. This process required several iterations with the research team and the e-prescribing software vendor.

\section{Physician focus groups}

Setting and sample: We implemented a purposive sample for focus group participants. For the first focus group conducted in April 2008, we recruited physicians attending the annual meeting of the Rhode Island Academy of Family Physicians (RIAFP). Physician participants were recruited through an advertisement placed in the RIAFP newsletter with subsequent email follow-up. Participants eligible for the focus group used e-prescribing software, but not necessarily the software of our research partner, DrFirst (DrFirst, Inc., Rockville, Maryland, USA). The first focus group included 11 participants. For the second focus group, we included six users of DrFirst's RCopia software from Massachusetts. For both focus groups, a US $\$ 100$ incentive was provided to participants. We originally had planned for additional focus groups; however, we reached saturation after conducting two.

Focus group script development: After conducting a systematic review of the literature, our multidisciplinary project team prepared a core list of open-ended questions to serve as the script for the focus group. Questions were included about the triggers and algorithms that were being developed including their general knowledge of the Beers criteria drugs, as well as workflow issues.

Conduct of focus groups: Standard focus group procedures were used with focus groups about $2 \mathrm{~h}$ in length and held over dinner. ${ }^{10}$ An experienced focus group moderator (REG) facilitated each session and was assisted by members of the research team (CE, BQ, AH). Consent forms and anonymous demographic data forms were completed by participants. An open-ended approach was used to elicit participants' opinions about the issues experienced with older patients and their medications from the moderator, complemented by spontaneous question probes or additional questions to follow new lines of inquiry raised by the focus group participants. Focus groups were recorded and professionally transcribed. Transcripts were checked for accuracy.

Analysis of focus group data: We conducted a group method of data analysis known as immersion/crystallisation. ${ }^{11}$ We analysed each focus group discussion in its entirety, thus maintaining awareness of the overall context of each speaker's comments within the whole of the discussion. In addition, the qualitative software NVivo was used to code the transcripts line-by-line. ${ }^{12}$ To enable this process to go forward, research team members independently listened to the focus group recordings and/or read the transcripts multiple times. We discussed each focus group, comparing the data between them, to search for emerging themes and findings relevant to the development of algorithms for the project.

\section{RESULTS}

While physicians in the focus groups on the whole claimed that triggers and evidenced-based treatment algorithms incorporated into their electronic medical record system would be useful in their practice, they clearly indicated that the triggers must be carefully designed to promote efficiency and reduce redundancy. A physician asserted, "Something pops up, gives you a little tutorial-it has to be short and sweet, something you can read in 30 s."And another explained, "You want to provide a little more information, but you can't have it so long, in providing every explanation... . We don't want that because all you're gonna do is click on little boxes, saying 'I don't care, I don't care'.

Participants described the frustration of receiving triggers and alerts about information that they were well aware of, alerts that were repetitive because of the frequency of the condition among patients or because the alert came up every time they saw particular patients, and from receiving alerts claiming that they had prescribed inappropriately when in fact they had made a specific decision to treat the patient in such a manner. Clinicians in the focus groups suggested suppressing alerts for renewals of medication combinations that patients were currently taking and tolerating, as well as for alerts related to medications that were used for shortterm courses of therapy. We frequently heard the 
Table 1 Actual messages in e-prescribing software-benzodiazepines and anticholinergic medications

\begin{tabular}{|c|c|c|c|}
\hline Trigger drug & Short warning & $\begin{array}{l}\text { Text displayed if prescriber } \\
\text { presses the more button }\end{array}$ & $\begin{array}{l}\text { Alternative medications } \\
\text { shown }\end{array}$ \\
\hline $\begin{array}{l}\text { Alprazolam } \\
\geq 2 \mathrm{mg} / \text { day }\end{array}$ & $\begin{array}{l}\text { Warning-dose alert, } \\
\text { increased sensitivity } \\
\text { in the elderly ... more }\end{array}$ & $\begin{array}{l}\text { 'Because of increased sensitivity } \\
\text { to benzodiazepines in elderly } \\
\text { patients, smaller doses may be } \\
\text { effective as well as safer. Total } \\
\text { daily doses should rarely exceed } \\
\text { the suggested maximum.' }\end{array}$ & Alprazolam $<0.75 \mathrm{mg}$ \\
\hline Diazepam & $\begin{array}{l}\text { Warning-prolonged } \\
\text { half-life in the elderly, } \\
\text { high fall risk ... more }\end{array}$ & $\begin{array}{l}\text { 'Older benzodiazepines (BZDP) such as } \\
\text { diazepam, have a prolonged half-life due } \\
\text { to their lipid solubility and the presence } \\
\text { of active metabolites. In elderly patients, } \\
\text { their half-life may potentially exceed } \\
\text { several days, resulting in prolonged } \\
\text { sedation and increasing the risk of falls } \\
\text { and fractures. Short- and intermediate- } \\
\text { acting BZDP are preferred if } \\
\text { a benzodiazepine is actually required.' }\end{array}$ & $\begin{array}{l}\text { Alprazolam } 0.125-0.25 \mathrm{mg} \\
\text { twice daily; not to exceed } 2 \mathrm{mg} \\
\text { every day } \\
\text { Buspirone } 5 \mathrm{mg} \text { twice daily, } \\
\text { up to } 20-30 \mathrm{mg} \text { every day; } \\
\text { not to exceed } 60 \mathrm{mg} \text { every day; } \\
\text { mg twice daily; not to exceed } \\
2 \mathrm{mg} \text { every day } \\
\text { Lorazepam:0.5 mg two to three } \\
\text { times a day; not to exceed } \\
3 \text { mg/day } \\
\text { Oxazepam: } 10 \text { mg two to } \\
\text { three times a day; not to } \\
\text { exceed } 60 \mathrm{mg} / \text { day }\end{array}$ \\
\hline $\begin{array}{l}\text { Cyclobenzaprine } \\
\text { (Flexeril, McNeil } \\
\text { Consumer and } \\
\text { Specialty } \\
\text { Pharmaceuticals, } \\
\text { Fort Washington, } \\
\text { PA) }\end{array}$ & $\begin{array}{l}\text { Warning-high risk } \\
\text { of anticholinergic } \\
\text { reactions in the } \\
\text { elderly ... more }\end{array}$ & $\begin{array}{l}\text { 'Most skeletal muscle relaxants are } \\
\text { poorly tolerated by elderly patients. } \\
\text { Some drugs, including cyclobenzaprine, } \\
\text { may have anticholinergic adverse effects } \\
\text { as well as causing sedation and weakness. } \\
\text { Agents such as carisoprodol are } \\
\text { metabolised to meprobamate which } \\
\text { has a significant abuse potential. } \\
\text { Additionally, the effectiveness of these } \\
\text { drugs at dosages tolerated by elderly } \\
\text { patients is questionable. The long-term } \\
\text { safety and efficacy of skeletal muscle } \\
\text { relaxants for chronic low back pain is } \\
\text { unclear and not recommended.' }\end{array}$ & $\begin{array}{l}\text { Non-drug modalities } \\
\text { Acetaminophen or ibuprofen } \\
\text { Naproxen short term only }\end{array}$ \\
\hline Hydroxyzine & $\begin{array}{l}\text { Warning-high risk } \\
\text { of anticholinergic } \\
\text { reactions in the } \\
\text { elderly ... more }\end{array}$ & $\begin{array}{l}\text { 'Some non-prescription and prescription } \\
\text { antihistamines may have potent } \\
\text { anticholinergic properties. In addition to } \\
\text { traditional anticholinergic symptoms of } \\
\text { constipation, urinary retention, and } \\
\text { blurred vision, these drugs may cause } \\
\text { confusion and delirium, especially if other } \\
\text { drugs with anticholinergic properties } \\
\text { are present. Non-anticholinergic } \\
\text { antihistamines are preferred in elderly } \\
\text { patients especially when needing to treat } \\
\text { allergies chronically.' }\end{array}$ & $\begin{array}{l}\text { Loratidine } 10 \mathrm{mg} \text { every day; } \\
10 \text { mg every other day in renal } \\
\text { or hepatic failure } \\
\text { Cetirizine } 10 \mathrm{mg} \text { every day; } \\
\text { decrease by } 50 \% \text { in renal or } \\
\text { hepatic failure } \\
\text { Fexofenadine } 60 \text { mg twice } \\
\text { daily or } 180 \text { mg every day; } \\
60 \text { mg every day in renal failure }\end{array}$ \\
\hline $\begin{array}{l}\text { Oxybutynin } \\
\text { (regular release) }\end{array}$ & $\begin{array}{l}\text { Warning-high risk } \\
\text { of anticholinergic } \\
\text { reactions in the } \\
\text { elderly ... more }\end{array}$ & $\begin{array}{l}\text { 'Regular release products containing } \\
\text { oxybutynin, a urinary antispasmotic } \\
\text { agent, may be poorly tolerated by many } \\
\text { elderly patients. Anticholinergic effects } \\
\text { are common and include confusion and } \\
\text { agitation in addition to traditional } \\
\text { anticholinergic effects of constipation } \\
\text { and tachycardia. Additionally, their } \\
\text { effectiveness at doses tolerated by } \\
\text { elderly patients is questionable'. }\end{array}$ & $\begin{array}{l}\text { Ditropan XL, Ortho-McNeil } \\
\text { Pharmaceuticals, Raritan, NJ } \\
\text { Detrol LA, Pfizer, New York, NY } \\
\text { Solifenacin, } \\
\text { darifenacin, } \\
\text { trospium }\end{array}$ \\
\hline
\end{tabular}


Table 2 Actual messages in e-prescribing software-antidepressants

\begin{tabular}{|c|c|c|c|}
\hline Trigger drug & Short warning & $\begin{array}{l}\text { Text displayed if prescribers } \\
\text { presses the more button }\end{array}$ & $\begin{array}{l}\text { Alternative } \\
\text { medications } \\
\text { shown }\end{array}$ \\
\hline Amitriptyline & $\begin{array}{l}\text { Warning-high risk } \\
\text { of anticholinergic } \\
\text { reactions and sedation } \\
\text { in the elderly ... more }\end{array}$ & $\begin{array}{l}\text { 'Amitriptyline (as well as doxepin) should } \\
\text { not be used as first-line antidepressant } \\
\text { therapy in elderly patients because of } \\
\text { strong anticholinergic and sedative properties. } \\
\text { In addition, cardiac toxicity is more likely to occur } \\
\text { in the presence of underlying cardiac disease. } \\
\text { Amitriptyline and doxepin may cause significant } \\
\text { orthostatic hypotension in older adults even in } \\
\text { lower dosages, thereby increasing the risk of } \\
\text { falls and fractures. Although nortriptyline or } \\
\text { desipramine may be used if a TCA is required, } \\
\text { alternatives such as sertraline or citalopram } \\
\text { generally are preferred as they may be } \\
\text { safer in elderly patients.' }\end{array}$ & $\begin{array}{l}\text { Sertraline } \\
\text { Citalopram } \\
\text { Escitalopram } \\
\text { Mirtazepine } \\
\text { Buproprion }\end{array}$ \\
\hline Doxepin & $\begin{array}{l}\text { Warning-high risk } \\
\text { of anticholinergic } \\
\text { reactions and sedation } \\
\text { in the elderly ... more }\end{array}$ & $\begin{array}{l}\text { 'Doxepin (as well as amitriptyline) should } \\
\text { not be used as first-line antidepressant } \\
\text { therapy in elderly patients because of strong } \\
\text { anticholinergic and sedative properties. } \\
\text { In addition, cardiac toxicity is more likely to } \\
\text { occur in the presence of underlying cardiac } \\
\text { disease. Doxepin, and amitriptyline may cause } \\
\text { significant orthostatic hypotension in older adults } \\
\text { even in lower dosages, thereby increasing the risk } \\
\text { of falls and fractures. Although nortriptyline or } \\
\text { desipramine may be used if a TCA is required, } \\
\text { alternative antidepressants such as sertraline or } \\
\text { citalopram generally are preferred as they may be } \\
\text { safer in elderly patients.' }\end{array}$ & $\begin{array}{l}\text { Sertraline } \\
\text { Citalopram, } \\
\text { Escitalopram } \\
\text { Mirtazepine } \\
\text { Buproprion }\end{array}$ \\
\hline $\begin{array}{l}\text { Fluoxetine } \\
\text { (daily) }\end{array}$ & $\begin{array}{l}\text { Warning - prolonged } \\
\text { half-life in elderly, high } \\
\text { ADR risk ... more }\end{array}$ & $\begin{array}{l}\text { 'Although the daily administration of fluoxetine } \\
\text { in healthy older adults has been shown to be } \\
\text { safe and effective in clinical trials, concern exists } \\
\text { because of the prolonged half-life of fluoxetine } \\
\text { and nor-fluoxetine especially in more medically } \\
\text { complex elderly patients. In addition, a risk of } \\
\text { producing excessive CNS stimulation, sleep } \\
\text { disturbances, and increasing agitation exists } \\
\text { especially with daily fluoxetine. Fluoxetine may } \\
\text { also cause multiple drug interactions. Safer } \\
\text { alternatives such as sertraline or citalopram exist.' }\end{array}$ & $\begin{array}{l}\text { Sertraline } \\
\text { Citalopram, } \\
\text { Escitalopram } \\
\text { Mirtazepine } \\
\text { Buproprion }\end{array}$ \\
\hline
\end{tabular}

following sentiment, "Don't keep showing the same ones over and over again."

Physicians repeated over and over the need for the data to be accurate and useful, "It would depend on how reliable we would perceive that data to be. Judging from other insurance data we get, it's pretty poor in terms of the accuracy of that."

Another physician said, "Differentiate it from the usual. There's an interaction here, you know, nonsteroidals and antihypertensives - we all know that. Quit doing that. It's annoying. Only if it's actually helpful. If this person has a serious side effect. And that's the only reason it (the alert) went up, and it really meant something, then yes (it's useful)."
A physician who approved of getting computer triggers nevertheless warned about ease of use,

I think that information would be extremely important.... So I think the information would have to be readily available, not having to be looked for, not physiciandependent, it really needs to be something brought to me by the prescreening technicians, and that information is on the chart $-4 / 5$ prescriptions filled, zero prescriptions filled... . All I need is the data.

Some physicians felt that having medication-related triggers on the computer at the time of the visit would aid them in counselling patients who were non-adherent with their medication therapy, 


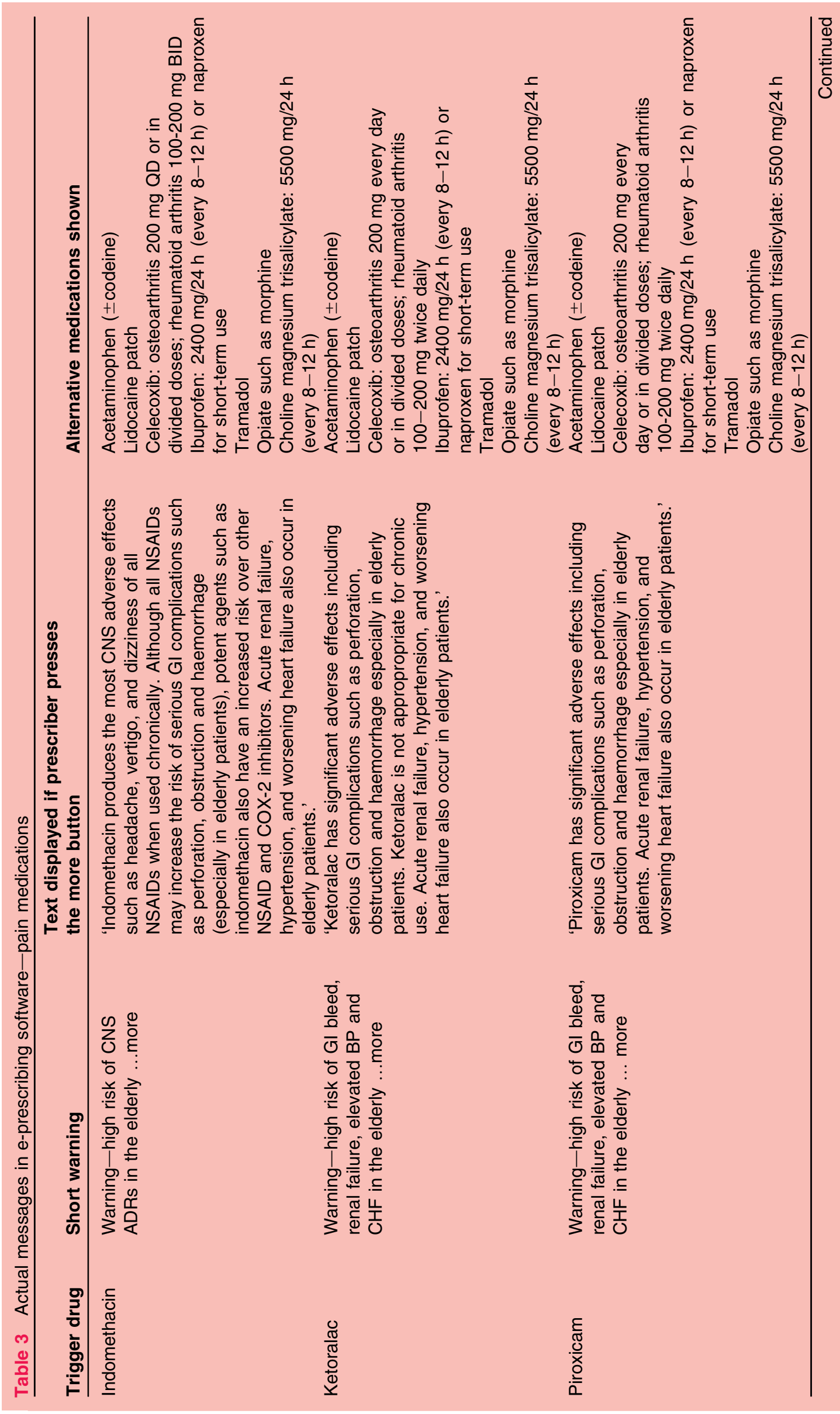




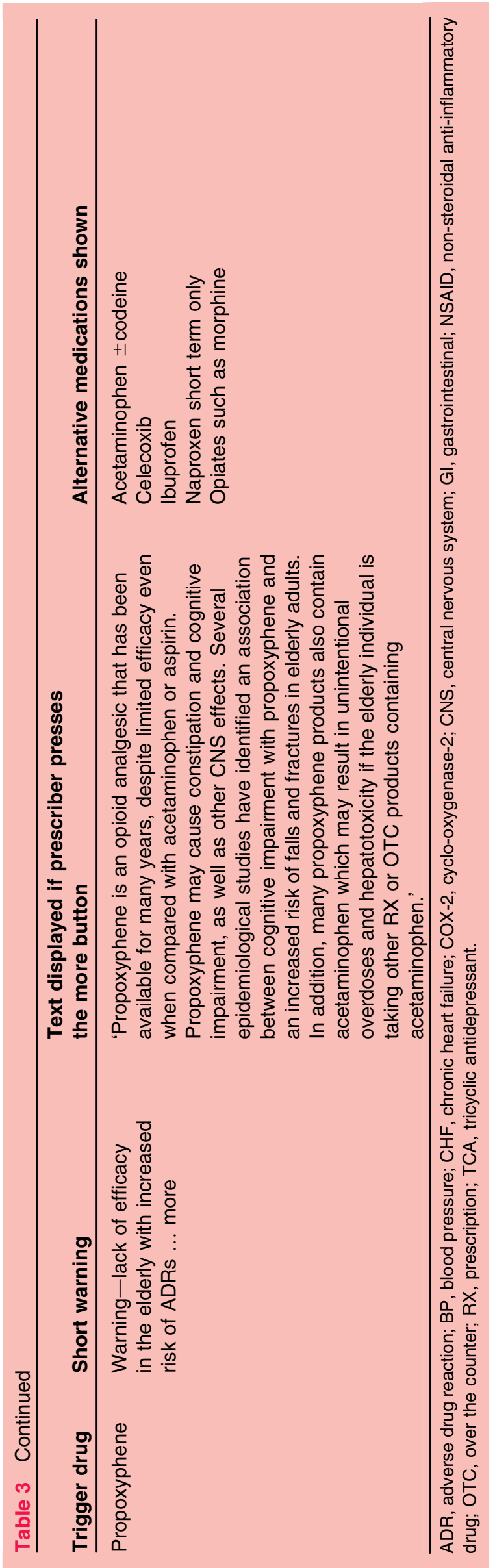

“A lot of patients don't want to bother the doctor... So a patient comes in and we see that there's significant progression of their disease. So we're assuming they're not taking their medication till they come to the office, the night before. To make me happy. They're treating me, they're not treating themselves... . There's some reason they're not telling me... . So if we had some information that we could broach with them, and we could say 'Why aren't you filling your prescriptions?"

Of note, many of the physicians in the focus groups were not specifically aware or knowledgeable of the term, Beers criteria drugs, although they recognised that the drugs were older and less commonly prescribed.

Online figures $1-15$ provide the treatment algorithms for each of the targeted medications or groups of medications. For each medication, the screen initially shows a short alert in a red font such as 'WARNING-Dose Alert, Increased Sensitivity In The Elderly...MORE' (tables 1-4). Clinicians then press a button to get more information about the alert in the form of a concise explanation about the specific issue with the drug that would make it potentially inappropriate for older adults. Several alternative medications are then shown on the screen with the intent to aid prescribers in easily identifying a potentially more appropriate drug therapy for the older patient. The one group of PIMs that lack appropriate alternatives was the skeletal muscle relaxants which are only minimally effective and have safety issues in older adults. Prescribers are alerted to try non-pharmacological alternatives.

\section{DISCUSSION}

Overall, the discussion from the focus groups indicated that triggers and evidenced-based treatment algorithms would be well received by primary care physicians if the triggers were focused on highly critical information, could be trusted to provide high accuracy, and were designed to promote efficient information retrieval. These findings provide support that implementation of these algorithms as a tool for physicians in a clinical setting is feasible. Clinicians recognise that electronic alerts at the point of prescribing have the potential to improve patient safety in the ambulatory setting. ${ }^{8-13} \mathrm{~A}$ survey of Massachusetts clinicians indicated that $30 \%$ had recently modified a potentially dangerous drug as a result of an electronic alert. ${ }^{8}$ Despite recognising the potential value of alerts, clinicians often override e-prescribing alerts because of lack of specificity of the messages or irrelevance of the medication to the current drug regimen. ${ }^{8} 13$ Prior research indicates that such alerts are frequently overridden (49-96\% of cases) because of poor specificity and high volume of alerts. ${ }^{7}$

In selecting drugs as triggers for potentially inappropriate use in older adults, we chose to use the Beers 


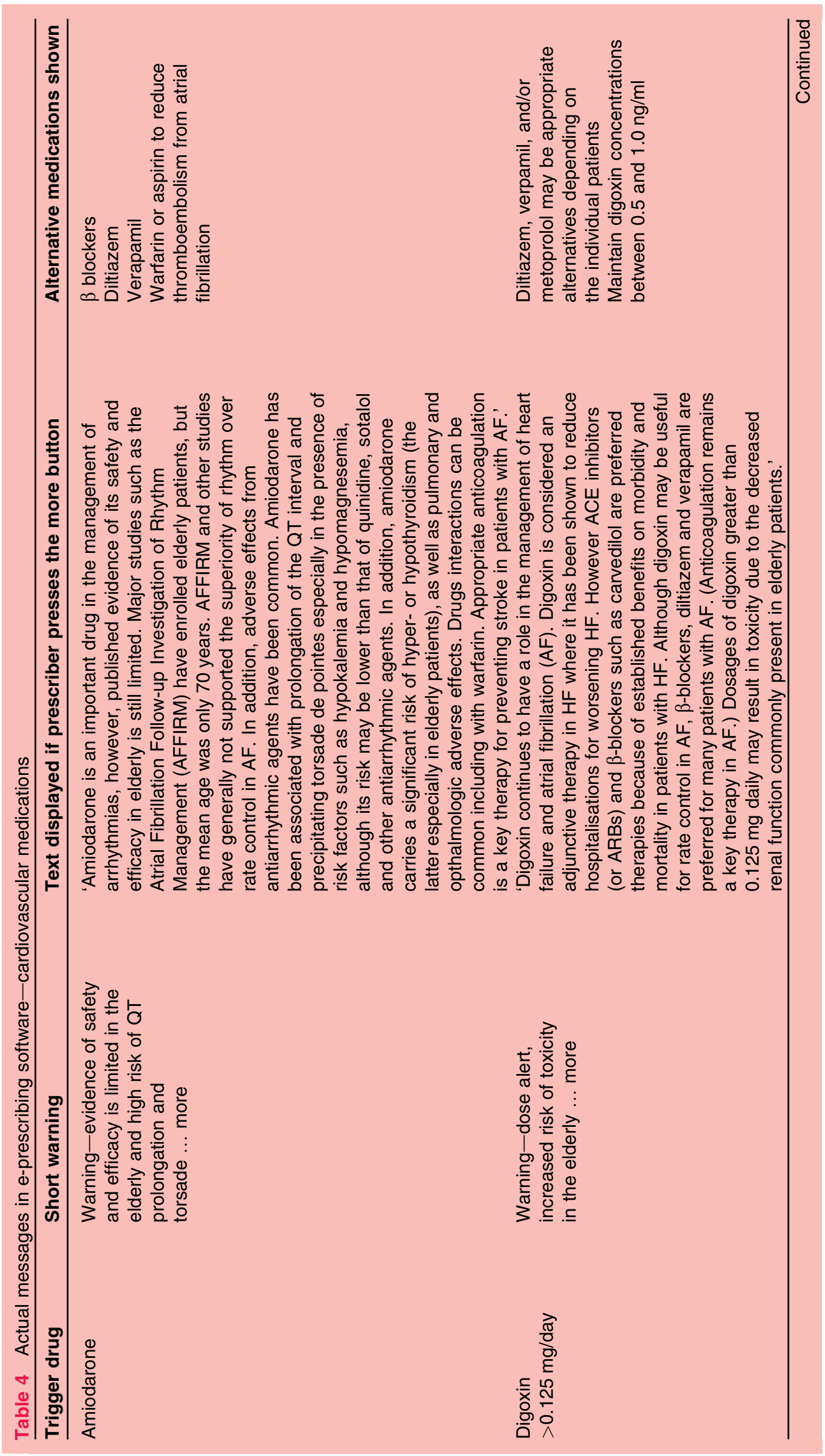




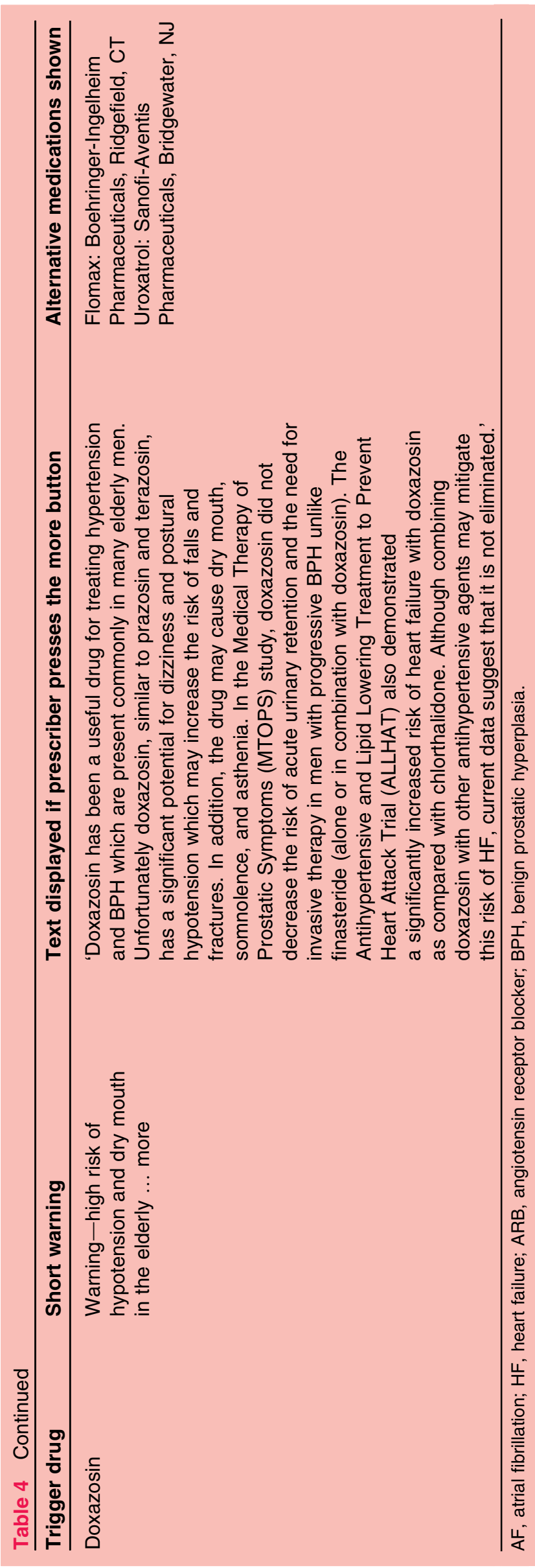

criteria drugs because the available e-prescribing software could easily identify these medications. Although a recent comparison between drugs - to avoid criteria such as Beers and Zhan with expert assessments of problematic prescribing-demonstrated the limitations of these criteria to measure prescribing quality, ${ }^{9} 1415$ they have value in making initial prescribing decisions. In addition, a study of two large outpatient practices using electronic health records has identified that $23 \%$ of elderly patients receive at least one potentially inappropriate medication, as defined by the Beers criteria. ${ }^{16}$ The health outcomes associated with the use of the Beers criteria have been associated with $\mathrm{ADE}$ in independently living elderly. ${ }^{17}$ Although there were other areas of inappropriate medication use that we were interested in exploring, the available standalone e-prescribing software was limited in which medication alerts we could effectively implement because we did not have information such as diagnosis or indication of the medication.

E-prescribing alerts need to be flexible and specific. These points are consistent with desires of primary care providers in the VA system and in community settings. ${ }^{13} 18$ Alerts were designed so that clinicians can easily recognise the severity of the alert with the use of colours. Increasing the greater specificity of alerts or reducing alert overload may lead to less over-riding. E-prescribing software that permits the clinician to set the desired alerting threshold has lower reports of overriding alerts. ${ }^{13}$ We also designed the alerts to minimise workflow disruption and so that they would not require additional clicking. We know that drug alerting systems targeting specific issues and minimising workflow disruptions increase clinician acceptance of alerts in ambulatory settings. ${ }^{7}$

Similar to previous reports, ${ }^{19}$ clinicians in our focus groups suggested suppressing alerts for renewals of medication combinations that patients currently tolerate. Providers noted that short-term courses of therapy would continue to arise in the alerts, suggesting that the time frame for medication history on which the drug alerts are run should be evaluated. If the e-prescribing technology has the drug-alerting component run on the entire medication history in the patient's electronic health record, it may actually exacerbate the problem of alert 'overloading' of the clinician. The best solution may be for computer software products for prescribers to run drug alerts only on the medications that the patient is currently taking (ie, an active medication list), instead of all of the medications that the patients have ever taken according to the electronic health record.

Considering the process of drug alerting at the point of prescribing in ambulatory settings is important. First, adding these alerts does not shift the work of evaluating the potential for medication harm upstream (from the 
pharmacist to the prescriber). The Omnibus Budget Reconciliation Act of 1990 requires pharmacists to perform a drug use review to evaluate prescribed drug therapy before dispensing to ensure that therapy is medically necessary, appropriate, and not likely to result in an adverse event. Specifically, pharmacists evaluate therapeutic duplication, therapeutic appropriateness, drug-allergy interactions, drug-disease contraindications, drug-drug interactions, correct dosage and duration of therapy, utilisation, abuse, and appropriate use of generic products. ${ }^{20}$ Thus, any product enhancements that involve alerting provide an additional layer of checking, not a substitution for checking.

The following limitations of the data should be considered. All physicians in this study were currently using e-prescribing software and represented a convenience sample. As such, the participants are likely to represent the most experienced e-prescribing users in primary care settings. Also, because scientific knowledge is dynamic, the treatment algorithms shown and alternative therapies recommended are time sensitive.

\section{CONCLUSION}

In a recent national study providing comprehensive estimates of ADE-related ambulatory visits, including visits to office-based clinics, hospital outpatient clinics, subspecialty clinics, and emergency departments, patients 65 years and older had an incidence of ADE visits as high as 1 in 20 persons. $^{21}$ Further, ADEs in patients over 65 years of age were associated with substantial morbidity with a quarter of patients requiring admission. ${ }^{21}$ E-prescribing adoption in the USA is increasing because of funding initiatives and other policy initiatives of the federal government. Enhancements to e-prescribing software technology will help clinicians avoid preventable ADEs. By increasing the specificity of the alerts and providing alternative treatment suggestions, clinicians believe that such alerts will assist in clinical decision-making.

Acknowledgements The authors acknowledge the valuable assistance of Norma Owens, PharmD, FCCP, BCPS and Erica Estus, PharmD, CGP in reviewing the triggers and alternative drug therapy recommendations.

Funding This study was supported in part by a grant from the Agency of Healthcare Research and Quality (1R18 HS017150) (Agency for Healthcare Research and Quality 540 Gaither Road Rockville, MD 20850) and the award number UL1RR031990 from the National Center for Research Resources, National Institutes of Health (9000 Rockville Pike Bethesda, MD 20892, USA). The funders had no involvement in the study design; in the collection, analysis and interpretation data; in the writing of the report; and in the decision to submit the paper for publication. Other Funders: NIH.

Competing interests None.
Patient consent Obtained.

Ethics approval This study was conducted with the approval of the Virginia Commonwealth University and Memorial Hospital of Rhode Island.

Contributors All the authors listed made a substantial contribution to the following: conception and design, acquisition of data or analysis and interpretation of data; drafting the article or revising it critically for important intellectual content; final approval of the version published.

Provenance and peer review Not commissioned; externally peer reviewed.

\section{REFERENCES}

1. Gandhi TK, Weingart SN, Borus J, et al. Adverse drug events in ambulatory care. N Engl J Med 2003;348:1556-64

2. Gurwitz JH, Field TS, Harrold LR, et al. Incidence and preventability of adverse drug events among older persons in the ambulatory setting. JAMA 2003;289:1107-16.

3. Field TS, Gilman BH, Subramanian S, et al. The costs associated with adverse drug events among older adults in the ambulatory setting. Med Care 2005;43:1171-6.

4. Thomsen LA, Winterstein AG, Sondergaard B, et al. Systematic review of the incidence and characteristics of preventable adverse drug events in ambulatory care. Ann Pharmacother 2007;41:1411-26.

5. Surescripts. Progress Reports. http://www.surescripts.com/about-eprescribing/progress-reports/national-progress-reports.aspx (accessed 19 Aug 2010).

6. Grossman JM. Even when physicians adopt e-prescribing, use of advanced features lags. Center for Studying Health System Change. http://www.hschange.com/CONTENT/1133/\#ib2 (accessed 21 Jun 2011).

7. van der Sijs $\mathrm{H}$, Aarts J, Vulto A, et al. Overriding of drug safety alerts in computerized physician order entry. J Am Med Inform Assoc 2006;13:138-47.

8. Weingart SN, Simchowitz B, Shiman L, et al. Clinicians' assessments of electronic medication safety alerts in ambulatory care. Arch Intern Med 2009;169:1627-32.

9. Fick DM, Cooper JW, Wade WE, et al. Updating the Beers criteria for potentially inappropriate medication use in older adults: results of a US consensus panel of experts. Arch Intern Med 2003;163:2716-24.

10. Kreuger R. Focus Groups: A Practical Guide for Applied Research. Thousand Oaks, CA: Sage Publications, 1994.

11. Borkan J. Immersion/crystallization. In: Crabtree B, Miller W, eds. Doing qualitative research. 2nd edn. Thousand Oaks, CA: Sage Publications, 1999:179-94.

12. QSR NVivo. Melbourne, Australia: QSR International Pty Ltd, 2000.

13. Lapane $\mathrm{KL}$, Waring ME, Schneider $\mathrm{KL}$, et al. A mixed method study of the merits of e-prescribing drug alerts in primary care. J Gen Intern Med 2008;23:442-6.

14. Zhan C, Sangl J, Bierman AS, et al. Potentially inappropriate medication use in the community-dwelling elderly: findings from the 1996 Medical Expenditure Panel Survey. JAMA 2001;286:2823-9.

15. Steinman MA, Rosenthal GE, Landefeld CS, et al. Agreement between drugs-to-avoid criteria and expert assessments of problematic prescribing. Arch Intern Med 2009;169:1326-32.

16. Buck MD, Atreja A, Brunker CP, et al. Potentially inappropriate medication prescribing in outpatient practices: prevalence and patien characteristics based on electronic health records. Am J Geriatr Pharmacother 2009; 7:84-92.

17. Jano E, Aparasu RR. Healthcare outcomes associated with Beers' criteria: a systematic review. Ann Pharmacother 2007;41:438-47.

18. Spina JR, Glassman PA, Belperio $P$, et al; Primary Care Investigative Group of the VA Los Angeles Healthcare System. Clinical relevance of automated drug alerts from the perspective of medical providers. Am J Med Qual 2005;20:7-14.

19. Bell DS, Cretin S, Marken RS, et al. A conceptual framework for evaluating outpatient electronic prescribing systems based on their functional capabilities. J Am Med Inform Assoc 2004;11:60-70.

20. National Association of Boards of Pharmacy. Information packet: omnibus budget reconciliation counseling and drug use review requirements. Park Ridge, IL. Pub L No. 101-508. 104 Stat 1388, 4401. 1992.

21. Bourgeois FT, Shannon MW, Valim C, et al. Adverse drug events in the outpatient setting: an 11-year national analysis. Pharmacoepidemiol Drug Saf 2010;19:901-10. 